\title{
Erratum to: A box-constrained differentiable penalty method for nonlinear complementarity problems
}

\author{
Boshi Tian ${ }^{1} \cdot$ Yaohua $\mathrm{Hu}^{2} \cdot$ Xiaoqi Yang ${ }^{3}$
}

Published online: 17 June 2015

C Springer Science+Business Media New York 2015

\section{Erratum to: J Glob Optim \\ DOI 10.1007/s10898-015-0275-6}

Unfortunately, Dr. X. Yang had been affiliated to "Business School of Hunan University" in the original article but Dr. X. Yang is affiliated only to "The Hong Kong Polytechnic University" as mentioned in this erratum.

The online version of the original article can be found under doi:10.1007/s10898-015-0275-6.

$凶$ Boshi Tian

tianboshi@126.com

Yaohua $\mathrm{Hu}$

hyh19840428@163.com

Xiaoqi Yang

mayangxq@polyu.edu.hk

1 Business School of Hunan University, Changsha 410082, Hunan, People's Republic of China

2 Department of Mathematics, Zhejiang University, Hangzhou 310027, People's Republic of China

3 Department of Applied Mathematics, The Hong Kong Polytechnic University, Kowloon, Hong Kong, People's Republic of China 